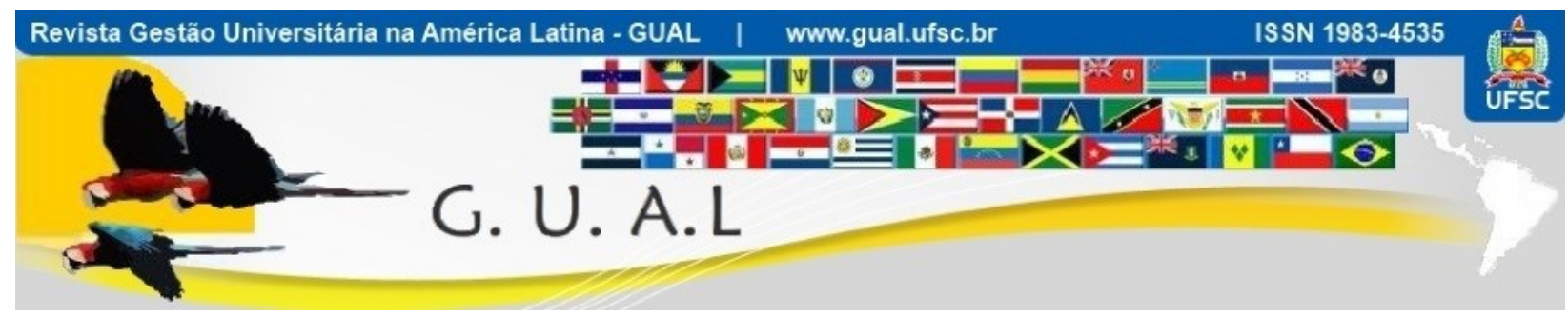

DOI: http://dx.doi.org/10.5007/1983-4535.2016v9n1p211

\title{
O PROCESSO DE FORMAÇÃO DE ESTRATÉGIAS EM INSTITUIÇÕES DE ENSINO SUPERIOR
}

\section{THE PROCESS OF STRATEGY TRAINING IN HIGHER EDUCATION INSTITUTIONS}

\author{
Ricardo Antonio De Marco, Mestre \\ Universidade do Oeste de Santa Catarina - UNOESC \\ vicereitor.cco@unoesc.edu.br \\ Gabriela Gonçalves Silveira Fiates, Doutora \\ Universidade Federal de Santa Catarina - UFSC \\ gabriela.fiates@ufsc.br
}

Recebido em 28/abril/2014

Aprovado em 24/setembro/2015

Sistema de Avaliação: Double Blind Review

Esta obra está sob uma Licença Creative Commons Atribuição-Uso. 


\title{
RESUMO
}

Este artigo objetivou analisar o processo de formação de estratégias nas Instituições de Ensino Superior de Santa Catarina. A pesquisa é de cunho quantitativo, e a partir dos dados coletados com um survey, a análise foi realizada com estatística multivariada. Os resultados demonstram que o processo real de formação de estratégias caracteriza-se como um processo planejado, fortemente influenciado pelo ambiente tarefa e pelas variáveis do ambiente geral. Concluiu-se que as IES estudadas percebem sua estratégia como sustentada pelo processo planejado de formação de estratégias; apesar disso parece afastar-se do processo como formação e aproximar-se do processo como formulação de estratégias.

Palavras-chaves: Instituições. Ensino Superior. Estratégia.

\begin{abstract}
This article aims to analyze the process of training strategies in higher education institutions of Santa Catarina. The research is quantitative nature, and from the data collected through a survey, the analysis was performed using multivariate statistics. The results demonstrate that the actual process of training strategies is characterized as a planned process strongly influenced by work environment and the general environment variables . It was concluded that the studied HEI realize its strategy as supported by the planned process of training strategies ; nevertheless seems to depart from the process as training and approach of the process as formulation strategies
\end{abstract}

Keywords: Institutions. Higher Education. Strategy. 


\section{INTRODUÇÃO}

O setor de ensino superior passou recentemente por expressivas mudanças, devido à promulgação da Lei de Diretrizes e Bases para Educação Nacional n. 9.394/96. A partir da entrada em vigor desta lei, aumentou a concorrência no setor com o surgimento e/ou ampliação das Instituições de Ensino Superior (IES). Segundo os dados do Censo do Ensino Superior INEP/MEC de 2005, o Brasil contava em 1995 com 894 IES, sendo 210 de cunho público e 684 privadas. Em 2005, o número aumentou para 2.165 IES, sendo 231 públicas e 1.934 privadas. Ou seja, no perído, o número de IES públicas aumentou 10\%, o setor privado aumentou sua participação em 116\%. Conforme Esteves (2007), essa forte expansão do número de organizações aumentou a competição entre as IES de ensino privado no Brasil em um segmento marcado até então por um ambiente de estabilidade e baixa concorrência.

Entretanto, números do Censo do Ensino Superior INEP/MEC de 2008 demonstram comportamento diferente: no ano de 2008, por exemplo, houve uma diminuição de 29 IES em relação ao ano de 2007, passando de 2.225 IES em 2007 para 2.196 IES em 2008. Tal diminuição pode ser explicada pela integração de instituições, por fusão ou compra, observada nos últimos anos. Cabe ressaltar, contudo, que a variação no número de IES dos últimos anos não se refletiu na oferta de vagas. De acordo com o Censo de 2008, o número total de vagas ofertadas em 2008 foi de 2.985.137, o que correspondeu a um incremento de 161.195 (5,7\%) em relação ao ano anterior. (Brasil, 2008).

Considerando tais mudanças no Brasil, percebe-se um movimento no sentido de adaptação a este novo contexto mais competitivo, implicando a necessidade de mudanças de postura, de posicionamento estratégico e da forma de gestão.Assim, o objetivo desse trabalho é analisar o processo de formação de estratégias nas IES de Santa Catarina, com base nas mudanças propostas pela Lei de Diretrizes e Bases para Educação Nacional n. 9.394/96.

Assim, este artigo está estruturado em cinco etapas. Na primeira, é apresentada esta introdução, em seguida apresenta-se o referencial que sustenta este estudo, na terceira etapa a metodologia e os procedimentos metodológicos são descritos, a quarta etapa contempla a apresentação e a análise dos dados e finalmente as considerações finais.

\section{REFERENCIAL TEÓRICO}

Diversos trabalhos focaram o processo estratégico das IES. Bertucci (2001) analisou como determinadas estratégias de gestão utilizadas por universidades influenciam na 
efetividade de sua performance. Por sua vez, Anastácio (2003) desenvolveu um estudo que visou a identificar o impacto que as mudanças ocorridas no ambiente político-legal do sistema de ensino superior brasileiro a partir da Lei de Diretrizes e Bases da Educação - LDB (1996) sobre a formulação de estratégias. A análise e conclusões do trabalho afirmam que "[...] o impacto do ambiente político-legal sobre o processo de formulação estratégica é real, todavia, o grau varia de organização para organização, mesmo considerando-se organizações com características altamente similares" (ANASTÁCIO, 2003, p. 331).

Alperstedt e Cunha (1999) mostraram que as IES sofrem variações de desempenho de um período para outro, sofrendo grande influência das lideranças. Evidenciou-se, também, a relevância dos stakeholders, do estilo de gestão e do comportamento estratégico da organização em cada período. Estudo semelhante foi desenvolvido por Alperstedt; Martignago e Fiates (2006), que estudaram o processo de adaptação estratégica de uma instituição de ensino superior sob a ótica da teoria institucional.Outros textos que também tratam do tema aplicado às IES são Nogueira (2006); Cyrino et al. (2008); Montenegro e Bulgacov (2009); Mainardes, et al (2010). No entanto, antes de fazer uma análise do processo estratégico das IES é importante conhecer um pouco mais sobre o tema e por sua amplitude delimitar os preceitos teóricos que serão considerados nesta pesquisa.

Na concepção de Nicolau (2001), o objetivo em pesquisas sobre estratégia não diz respeito aos conceitos teóricos, mas ao modo como estas são concebidas e operacionalizadas. O autor também sustenta que a compreensão da estratégia na organização implica entender o processo interativo que ocorre entre pessoas, ambiente, organização e estratégia. Consoante, Mintzberg e Quin (2001) destacam que a estratégia é processo organizacional inseparável da estrutura, do comportamento e da cultura da organização.

Neste sentido, em relação ao processo de concepção de estratégias encontra-se na literatura algumas diferenças conceituais sobre a formulação e formação de estratégias. Enquanto a formulação de estratégias, de acordo com Chandler (1962); Ansoff (1965); e Mintzberg (1973) dentre outros, é concebido por meio de planos formais, prescritivos e sistemáticos. Esta perspectiva aproxima-se da postura de análise crítica do ambiente por meio da identificação de forças e fraquezas, oportunidades e ameaças, vistos inicialmente em Ansoff (1965) e amplamente difundidos por Porter $(1980,1985)$ por meio da análise estrutural da indústria. O processo de formulação de estratégias é guiado essencialmente por espectativas de retornos pré-estabelecidos e por objetivos e metas de curto, médio e longo 
prazos, consoante com os fundamentos do planejamento estratégico desenvolvidos por Chandler (1962); Steiner; Ansoff (1965); Mintzberg (1973) e Porter (1980, 1985).

O processo de formação de estratégias demonstrou uma abordagem mais esclarecedora a partir da perspectiva teórica Mintzberg e Quin (2001) sobre o “processo estratégico". Os autores destacam que o processo de formação de estratégias distancia-se de modelos prescritivos expressos em planos formais sustentados em análises criteriosas do ambiente e guiados por objetivos e metas, delineados por Chandler (1962); Ansoff (1965); Adrews (1971); Mintzberg (1973) e Porter (1980, 1985). De acordo com Mintzberg e Quin (2001), o processo de formação de estratégias é sustentado por elementos que aproximam-se de padrões evolutivos de aprendizado e interação do estrategista com a organização, em um processo dinâmico que evolui ao longo do tempo, sem plano formal como guia.

Mintzberg, Ahlstrand e Lampel (2000) corroboram com a distinção de formação e de formulação de estratégias, ao apresentarem o termo formação para se referir ao processo pelo qual as estratégias são criadas como um processo de emersão ou por um processo de planejamento consciente e explícito, ao qual chamam de formulação da estratégia.

Beppler; Pereira e Costa (2011, p.143) destacam que a “[...] formulação estratégica é abordada preponderantmente por autores clássicos, os quais a definem como um processo deliberado de escolha racional das estratégias consideradas ideais para o perfil da organização". Enquanto que a formação de estratégias para Beppler; Pereira, e Costa (2011, p.144) é "“...] retratada principalmente pela visão de autores processualistas, é considerada como processo descritivo, o qual não elabora intencionalmente as estratégias, e, sim, as percebe e legitima à medida em que ocorre uma série de padrões ao longo do tempo".

Dessa forma, percebe-se que o processo de criação de estratégias sustenta-se em duas grandes abordagens: processo deliberado e emergente. $\mathrm{O}$ processo deliberado fundamenta-se na busca formal das melhores alternativas e caminhos, pela utilização de instrumentos gerenciais analíticos para interpretar a realidade, o emergente por outro lado, destaca a possibilidade de criar estratégias em um processo contínuo de aprendizagem. A despeito desta diferença, o texto a seguir aborda ambos como formação em virtude dos autores que serviram de base para esta pesquisa não fazer essa distinção (NICOLAU, 2001; BARBERO, 2008).

A partir da verificação dos modos de formação de estratégia, pretende-se discutir os aspectos dos processos de criação de estratégias, consoante à classificação de Nicolau (2001), que apesar do grande número de abordagens sobre o tema, essa autora optou por três linhas: a formação de estratégia como processo formal; a formação da estratégia como processo 
negociado; e a formação da estratégia como processo de construção permanente. Por fim, apresenta-se, também, a formação de estratégia como processo de mudança.

a) A formação de estratégia como um processo planejado: formulação de estratégias: em conformidade com alguns dos principais pesquisadores acerca do planejamento estratégico como Ansoff (1965) e Porter (1980, 1985), as estratégias resultam de um processo controlado e consciente de planejamento formal, decomposto em elaborada sequência de etapas distintas, cada uma delineada por check lists e apoiada por técnicas estruturadas, a partir dos executivos, no topo da pirâmide organizacional. O entendimento é de que o planejamento estratégico, consolidado em um documento, proporciona uma estrutura unificada por meio da qual os gestores podem tratar os principais problemas da organização, identificar mais facilmente novas oportunidades, avaliar as forças que podem ser potencializadas e as fraquezas que devem ser corrigidas (NICOLAU, 2001).

b) A formação da estratégia como um processo negociado: conforme ponderado por Nicolau (2001), apresenta as etapas dos processos decisórios organizacionais oriundos das teorias sobre decisão, encontradas, por exemplo, em Simon (1947, 1971), March e Simon (1981), e outros. Para Simon (1971), o processo decisório pode ser pensado como composto de quatro fases distintas: 1. Inteligência; 2. Projeto; 3. Escolha; e 4. Implantação. Sem negar o processo formal, esse enfoque valoriza o processo de negociação a partir da concepção da empresa como um corpo social, de indivíduos que interagem politicamente (NICOLAU, 2001). Pettigrew (1977) concorda com esta concepção, e defende que a formação da estratégia nas organizações é processo contínuo e eminentemente político. Segundo ele, as estratégias emanam do processo decisório e dos diversos eventos acerca dos dilemas organizacionais.

c) A formação da estratégia como um processo de construção permanente: formação de estratégias. Considerando as limitações das abordagens anteriores, Nicolau (2001, p.11) destaca que: [...] a formação da estratégia é um processo complexo e que as perspectivas anteriores não capturam todas as suas dimensões. Enquanto o sistema de planejamento formal centra-se em fatores quantitativos, desvalorizando os aspectos qualitativos (comportamentais e organizacionais).

As relações comportamentais como processo permanente, coadunam-se à visão de Mintzberg (1978) de estratégias emergentes. O autor ressalta que as estratégias emergentes são aquelas que surgem sem que haja uma intenção definida, tendo como principal característica a sua base em um processo de tentativa e erro. Evolutivamente Mintzberg 
(1994) estabelece também que estratégia emergente é uma estratégia não planejada, que só é percebida como estratégia pela organização à medida que ela vai acontecendo e se concretiza.

d) A formação da estratégia como um processo de mudanças: Mintzberg, Ahlstrand, Lampel (2000) observam que as mudanças trazem novas combinações de circunstâncias para a organização. Os autores destacam que as mudanças ocorrem nas organizações ao longo do tempo, como reação adaptativa de um processo fragmentado, no qual as decisões são tomadas, com pouca consideração sobre metas definidas ou plano previamente estruturado. Tendo estabelecido as premissas teóricas que subsidiarão a pesquisa, sobretudo em sua fase de análise, passa-se agora a apresentação da metodologia.

\section{METODOLOGIA}

Este estudo, em seu processo, foi pautado pela filosofia positivista e pela lógica indutivo de análise, por conseguinte, adotou-se uma abordagem quantitativa de pesquisa. Em relação aos seus objetivos esta pesquisa caracteriza-se como descritiva, visto que este trabalho está focado na compreensão do fenômeno sob investigação conforme conceitos e construtos teóricos (ROSCH, 1999). E adicionalmente é um estudo explicativo, visto que busca identificar e explicar os fatores determinantes do processo estratégico.

A estratégia de pesquisa adotada foi o survey. Para a quantificação exata da população de IES do Estado de Santa Catarina foram consultadas as bases de dados do INEP BRASIL (2008) que apresentava um total de 73 IES. No entanto, para aferição, buscou-se junto à Associação de Mantenedoras Particulares de Educação Superior de Santa Catarina AMPESC e à Associação Catarinense das Fundações Educacionais - ACAFE os dados atuais, que apontaram em fevereiro de 2011 um total de 61. As causas para esta redução estão relacionadas principalmente às fusões e incorporações entre IES, além da extinção de outras. Estas 61 IES estão classificadas de acordo com sua organização acadêmica da seguinte forma:

Tabela 1 Classificação das IES de acordo com a organização acadêmica

\begin{tabular}{lcc}
\hline Classificação de acordo com a organização acadêmica & $\begin{array}{c}\text { Número de IES em } \\
\text { Santa Catarina }\end{array}$ & $\begin{array}{c}\text { Número de IES que } \\
\text { retornaram }\end{array}$ \\
\hline Faculdades Integradas, Institutos e Escolas Superiores e & 43 & 28 \\
Centros de Educação Tecnológica - Privadas & & 11 \\
Universidades e Centros Universitários - Comunitárias & 15 & 02 \\
Universidades Públicas & 03 & $\mathbf{4 1}$ \\
Total & $\mathbf{6 1}$ & \\
\hline
\end{tabular}

Nota Fonte: INEP (2011); ACAFE (2011); AMPESC (2011). 
Para dar conta dos objetivos propostos foram selecionados os dirigentes das instituições que, pelas posições hierárquicas (de nível estratégico) que ocupam, detém amplo conhecimento do processo estratégico da instituição, garantindo, deste modo, que não haveria interferência ou desvio de foco nas respostas em relação ao processo estratégico. Assim, os respondentes caracterizam-se como os dirigentes principais das IES - Presidente da Fundação Mantenedora, Reitor, Vice-reitores de Campus, Diretores ligados ao nível estratégico e Sócioproprietário.

Como procedimento de coleta de dados, este trabalho utilizou um questionário estruturado, com questões fechadas e objetivas. O instrumento foi aplicado por e-mail diretamente aos indivíduos da amostra; foi efetuado contato telefônico com todos os respondentes; no pré-teste efetuado com 5 (cinco) dirigentes da Unoesc Campus de Xanxerê o tempo de duração para responder os questionários ficou entre $8 \mathrm{~min}$. e $12 \mathrm{~min}$, todos os questionários foram tabulados individualmente e tiveram tratamento estatístico.

Das 61 IES contactadas, 20 não responderam a pesquisa, destas a maioria argumentou que não publicizam suas estratégias e muito menos a forma como a definem em virtude da concorrência. Este número porém não a inviabilizou. $\mathrm{O}$ instrumento de coleta de dados está dividido em duas etapas: na primeira encontra-se o questionário que procurou reconhecer o processo de formação de estratégias das IES e a segunda parte refere-se aos condicionantes ambientais que influenciam esse processo.

A coleta dos dados foi construída e adaptada para o contexto desta pesquisa junto as IES a partir do trabalho de Barbero (2008) que estudou - formação de estratégias: uma contribuição por intemédio de um modelo multidimencional. Neste estudo o autor utilizou o método survey de pesquisa e o questionário foi estruturado por meio de escalas do tipo Likert.

A cada questão, o respondente foi solicitado a concordar ou discordar em uma escala de cinco pontos: (1) Discordo plenamente; (2) Discordo parcialmente; (3) Sou neutro; (4) Concordo parcialmente e (5) Concordo plenamente. Além destes cinco pontos será permitido ao respondente indicar "não sei - não se aplica".

A análise dos dados deste trabalho foi efetuada primeiramente em blocos agrupados de acordo com os processos discutidos em cada abordagem teórica: processo planejado de formação de estratégias, processo negociado de formação de estratégias, processo de construção permanente de formação de estratégias, processo de mudança de formação de estratégias e o último bloco contempla as condicionantes ambientais. Por fim, foi realizada a análise fatorial, multidimensional, clusters e os testes de hipótese conjunta. Deste modo, o 
processo de análise estatística deste trabalho será dividido em análise exploratória dos dados; análise descritiva dos dados e, por conseguinte, a análise estatística multivariada.A fim de estabelecer a relação entre os fatores e as variáveis que caracterizam o processo de formação de estratégias em IES, foi utilizada a análise estatística multivariada por meio do uso do software SPSS (Statistical Package for the Social Sciences) (MAROCO, 2010).

\section{RESULTADOS}

A análise conjunta dos 41 indicadores desta pesquisa compreende a verificação da efetividade das cargas fatoriais geradas em cada grupo/bloco para o processo real de formação de estratégias das IES pesquisadas. Inicialmente, são apresentados os resultados que demonstram a capacidade explicativa (representado pela comunalidade) de cada grupo/bloco a partir de seus indicadores analisados em conjunto, ou seja, a partir dos indicadores que apresentaram cargas fatoriais satisfatórias, permitindo perceber a contribuição desses indicadores para cada grupo/bloco e desses para o processo real de formação de estratégia das IES respondentes. Em seguida, será apresentada a análise de clusters e o escalonamento multidimensional (MDS), que demonstrará o agrupamento das IES respondentes, pelas proximidades das respostas. Por fim, serão avaliadas as hipóteses da pesquisa.

Antes de seguir com as análises, realizou-se o teste alplha de cronbach para todos os indicadores desta pesquisa, e o teste demonstrou um índice de confiabilidade de aproximadamente $67 \%$. Esse resultado demonstra que os indicadores, independente do grupo teórico que pertençam, apresentam resultados confiáveis, indicando que o construto $\mathrm{m}$ corresponde em torno de $67 \%$ do impacto real das variáveis sobre o fenômeno em estudo.

A seguir, apresenta-se a análise multivariada conjunta dos indicadores que, pelas cargas fatoriais individuais contribuem para explicar realmente como ocorre o processo de formação de estratégias das IES pesquisadas. Nesta fase da análise, os indicadores que apresentaram cargas fatoriais inferiores a 0,5 foram desconsiderados, visto que Maroco (2010) considera cargas fatoriais menores que 0,5 insignificantes para o contexto em análise.

Os resultados conjuntos dos dados demonstram que entre as quatro perspectivas teóricas (processo planejado, negociado, construção permanente e de mudanças) utilizadas por este trabalho que explicam o processo de formação de estratégias, a única que demonstrou consistência tanto pelas cargas fatoriais como pelas comunalidades geradas por seus indicadores isoladamente, foi o processo planejado de formação de estratégias. Esta 
constatação é evidenciada no gráfico a seguir que demonstra as cargas fatoriais e respectivas comunalidades desta constatação.

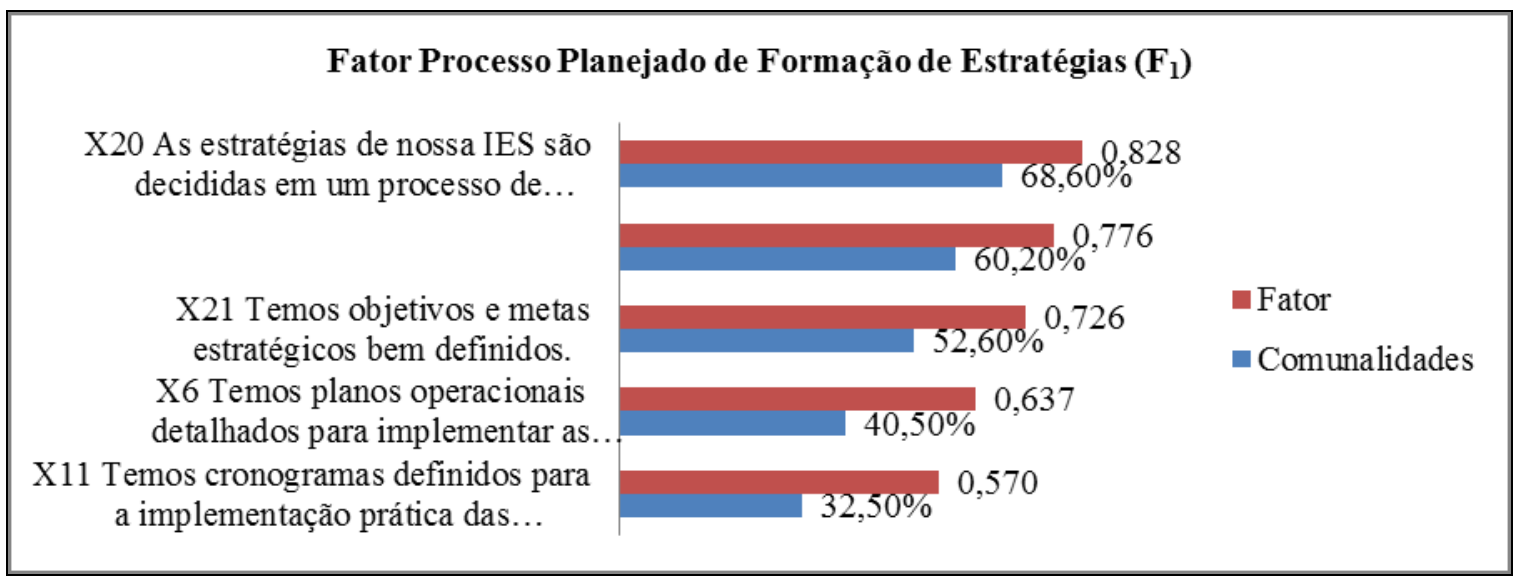

Gráfico 1 Fator processo planejado de formação de estratégias.

Fonte: elaborado pelos autores.

Por meio dos dados analisados, foi possível perceber que existem evidências que permitam afirmar que o processo de formação de estratégias das IES pesquisadas considera o processo planejado um fator $\left(\mathbf{F}_{1}\right)$ preponderante para a construção de suas estratégias, sendo guia para as decisões desta natureza.

A concentração da carga fatorial do indicador "20 - As estratégias de nossa IES são decididas em um processo de Planejamento Estratégico" - 0,828 -, que demonstra 68,6\% de capacidade explicativa é a demonstração clara da tendência pelo processo planejado, ou seja, é o indicador que mais contribui para justificar o fator planejado entre os respondentes.

Outrossim, as IES respondentes admitem comportamento formal e consciente de planejamento formal, decomposto em etapas, guiados por objetivos e metas a serem executadas e implementado por meio de planos operacionais, conforme as definições de alguns dos principais autores acerca do tradicional planejamento estratégico, Ansoff (1965), Steiner e Miner (1977), Hoffer e Schendel (1978), Porter (1980,1985).

Aproximam-se das definições de Mintzberg (1978); Mintzberg, Ahlstrand e Lampel (2000); Mariotti (2000) ; Mintzberg e Quin, (2001) de formulação deliberada de estratégias, que se fundamenta na busca formal das melhores alternativas e caminhos, pela utilização de instrumentos gerenciais analíticos para interpretar a realidade e responder reativamente ao contexto ambiental.

Nessa direção, a deferênça das IES respondentes ao vincularem o seu processo estratégico à "mensuração de retornos de curto, médio e longo prazo" (indicador 5); ao "foco 
em objetivos e metas" (indicador 21); "a implementação por meio de planos operacionais" (indicador 6); a "divisão de responsabilidades e a "cronogramas previamente definidos" (indicador 11), aproxima-se da visão processual de esquema organizado, normativo e sistemático para construir estratégias, que advém dos preceitos que Mintzberg, Ahlstrand e Lampel (2000) sintetizaram como: 1) estágio de fixação de objetivos; 2) estágio de avaliação externa e interna; 3) estágio de avaliação da estratégia (formulação); 4) estágio de operacionalização da estratégia e 5) estágio de programação do processo.

Conquanto, ao analisar o indicador "19 - Avaliamos racionalmente nosso ambiente: interno (forças e fraquezas) e externo (oportunidades e ameaças) antes de definir as estratégias. Exemplo: análise de concorrentes, mercado, etc.”, referente à análise do ambiente não tenha tido carga fatorial suficiente para ser confirmado, foi interessante perceber que, ao avaliar diversos indicadores específicos para este fim (contexto ambiental), um número mais significativo foi confirmado, inclusive possibilitando caracterizar o ambiente tarefa como um fator $\left(\mathbf{F}_{5}\right)$ determinante do processo estratégico.

Os pressupostos do fator planejado $\left(\mathbf{F}_{1}\right)$ são ratificados pela indicação das IES respondentes em assumir o grupo/bloco de indicadores que compreende a análise do contexto ambiental como elementos fundamentais para o seu processo estratégico, ainda que não apresente caráter de monitoramento e análise crítica destas variáveis, conforme sugere Porter (1980, 1985). O gráfico 2 apresenta o desempenho dos indicadores do ambiente geral e do ambiente tarefa.

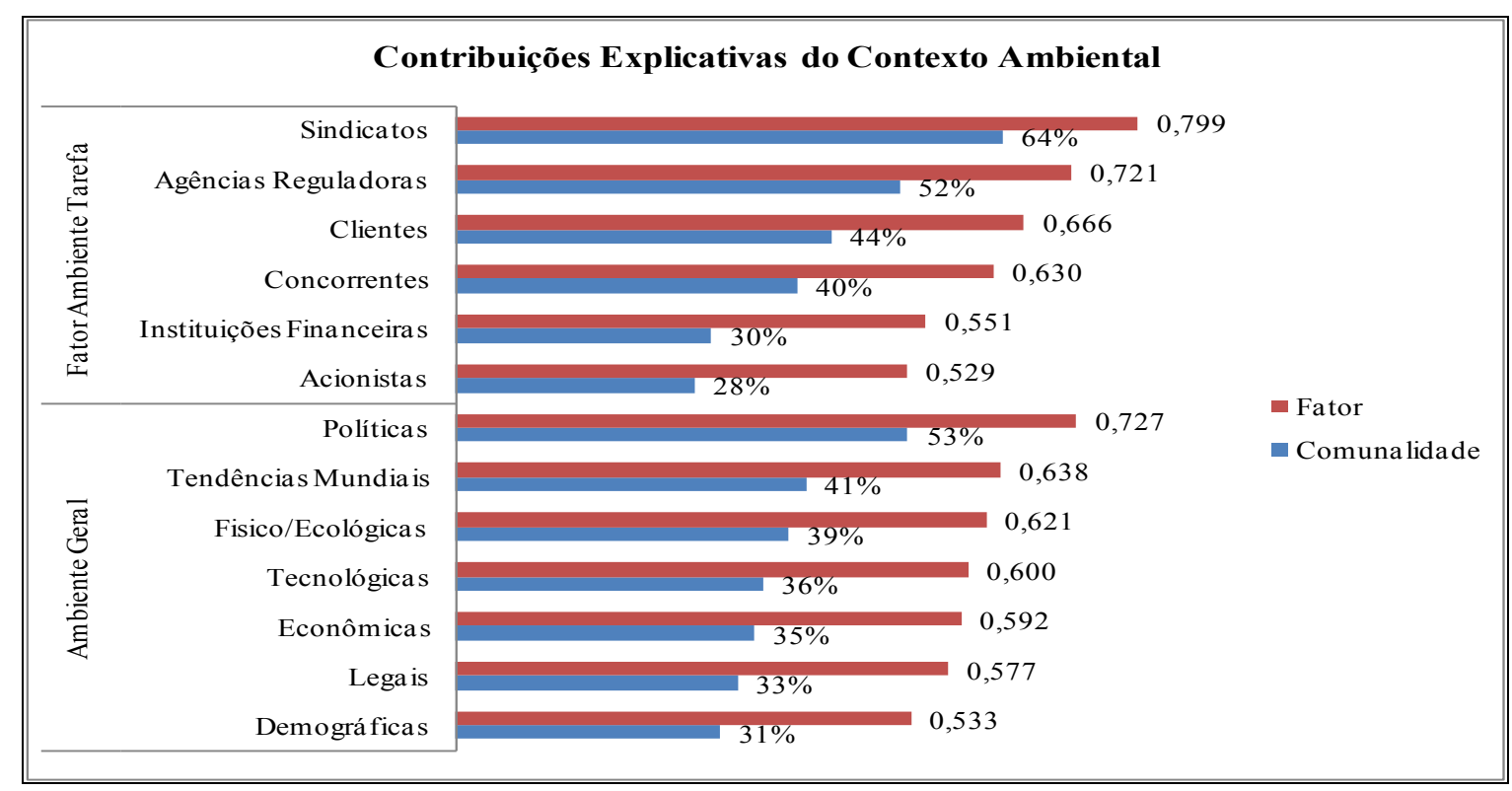

Gráfico 2 Contribuições explicativas do contexto ambiental. Fonte: elaborado pelos autores. 
A análise conjunta dos dados demonstrou que os indicadores do ambiente tarefa, confirmaram-se como um fator $\left.\mathbf{( F}_{5}\right)$ pelas cargas fatoriais e respectivas comunalidades geradas. Os indicadores do ambiente geral ficaram muito próximos de se caracterizarem como um fator $\left(\mathbf{F}_{\mathbf{6}}\right)$, entretanto, as cargas fatoriais analisadas conjuntamente não foram suficientes para tal feito. Evidenciou-se, no ambiente geral, que os respectivos indicadores isoladamente apresentaram altos índices fatoriais e, por conseguinte, altos índices de comunalidades, sugerindo que as IES respondentes admitem em seu processo estratégico a influência do ambiente geral em seu comportamento, o que mais uma vez surpreendeu a exclusão do indicador "19 - Avaliamos racionalmente nosso ambiente: interno (forças e fraquezas) e externo (oportunidades e ameaças) antes de definir as estratégias.

A influência do contexto ambiental, seja do ambiente tarefa ou do ambiente geral, confirma as constatações de Mainardes; Alves; Raposo e Domingues (2010) quando constataram a interferência dos stakeholders no processo estratégico de uma universidade. Ademais, esta análise aproxima-se das constatações de Freeman (1984) e Bonwditch e Buono (1997), de que as organizações não operam sozinhas no ambiente.

Confirma-se, por está análise, que existem forças atuantes no ambiente tarefa e no ambiente geral das IES respondentes, que de alguma forma influenciam os dirigentes no processo de formação de estratégias. Constatação que Mintzberg (2004) atribui a um agregado de coisas de condições e de interferências circunstanciais, que podem influenciar potencialmente as estratégias das organizações.

Do grupo de stakeholders identificados pela pesquisa, os sindicatos (0,799/64\%), políticas $(0,727 / 53 \%)$ e agências reguladoras $(0,721 / 52 \%)$, apresentaram a maior carga fatorial/comunalidade, ou seja, explicativa. Confirmam as constatações de Crubellate; Grave e Mendes (2004), que as estratégias surgem em decorrência da influência de padrões institucionais sobre as decisões, assim como a capacidade dos dirigentes em influenciar estes padrões institucionais. Neste caso, verifica-se que a legitimidade conferida ao contexto ambiental relaciona-se ao que Dimaggio e Powell (1996) chamou de campos organizacionais, enfatizando a influência de normas, de regulamentos e de aspectos coercitivos junto ao comportamento das organizações. Outros indicadores como clientes $(0,666 / 44 \%)$, concorrentes $(0,630 / 40 \%)$, tendências mundiais $(0,638 / 41 \%)$, aspectos físico/ecológicos $(0,621 / 39 \%)$ e tecnologias $(0,600 / 36 \%)$, perfazem um grupo intermediário em relação à carga fatorial e respectiva comunalidade. $O$ terceiro grupo de indicadores pela relação 
fator/comunalidade são as condições econômicas $(0,592 / 35 \%)$, os aspectos legais $(0,577 / 33 \%)$, as variáveis demográficas $(0,533 / 31 \%)$, as instituições financeiras $(0,551 / 30 \%)$ e os acionistas $(0,529 / 28 \%)$.

Percebe-se que, entre os stakeholder,s existe uma escala de importância atribuída pelos respondentes intuitivamente, constatada pela análise desta pesquisa, em que se destacam inicialmente os stakeholders relacionados às questões normativas; em posterior aparecem os stakeholders ligados às tendências e o comportamento de aspectos mercadológicos; por fim, aparecem os stakeholders que se relacionam com as variáveis econômicas e de interesses financeiros. Os stakeholders identificados neste estudo coadunam-se com as constatações de Alperstedt; Martignago e Fiates (2006) ao observaram que as estratégias de uma IES tiveram a influência de seis stakeholders: comunidade, lideranças políticas, governo, colaboradores, alunos e os concorrentes, e os fatores institucionais sobressaíram-se como nesta pesquisa.

$\mathrm{Na}$ sequência da análise conjunta dos dados, apresenta-se os indicadores que, isoladamente, confirmaram sua relevância explicativa pelas cargas fatoriais e respectivas comunalidades do processo negociado, de mudanças e de construção permanente.

A análise conjunta dos dados ratificou que os indicadores do processo de mudanças de formação de estratégias pelas cargas fatoriais e comunalidades, " $\mathrm{X}_{10}$ : Não temos como mudar nosso ambiente de negócios, somos conduzidos pelo mercado" $(0,877 / 77 \%)$ e " $\mathrm{X}_{12 \text { : Nossa }}$ liberdade para fazer escolhas é restringida porque o ambiente externo à empresa (mercado, concorrência, governo, etc.) determinam as direções” $(0,725 / 60 \%)$, contribuem significativamente para explicar o processo real de formação de estratégias das IES.

Por esta constatação, percebe-se que as IES respondentes apresentam muitas dificuldades em lidar com o contexto ambiental, especialmente com as mudanças que ocorrem nesse ambiente. Esta análise demonstra que o ambiente condiciona o comportamento estratégico das IES respondentes, ou seja, as estratégias são determinadas pelo ambiente, elas se impõem, conforme Porter (1980) e Hinings; Greenwood (1989). Fato que se aproxima do padrão deliberado de formação de estratégias, Mintzberg, Ahlstrand e Lampel (2000).

Surge com bastante clareza à postura normativa e formal caracterizada por Hit e Tyller (1991). Decorre deste comportamento um processo estratégico centrado em planos formais, com a análise crítica do ambiente, guiados por objetivos e metas (MINTZBERG, AHLSTRAND; LAMPEL, 2000).

Da mesma maneira é possível perceber a presença, nas IES respondentes, de comportamento isomórfico de atuação estratégica, em que prevalecem as forças imitativas, 
normativas e coercitivas, conforme Hinings e Greenwood (1989). Elementos que evidenciam postura reativa e deliberada de formação de estratégia, em que as estratégias são selecionadas e impostas pelo ambiente, conforme os argumentos de Aldrich e Pfeffer (1976). Elementos que sugerem estratégias com caráter deterministas, conforme as definições de Hinings e Greenwood (1989). Aliam-se às prerrogativas ambientais do processo de mudanças, verificados até aqui, a confirmação da influência dos indicadores do processo de construção permanente que valorizam a interferência da perspectiva do contexto ambiental como elemento importante no processo estratégico das IES pesquisadas.

$\mathrm{O}$ indicador " $\mathrm{X}_{14:}$ As estratégias de nossa IES são continuidade dos padrões de ação do passado" (0,722/52\%), confirma as considerações de Mintzberg; Quinn (2001), em que as estratégias são construídas de maneira evolutiva na medida em que aspectos do ambiente interno e eventos externos fluem simultaneamente, aproximando-se da premissa do aprendizado de Mintzberg, Ahlstrand e Lampel (2000). Os indicadores " $\mathrm{X}_{15 \text { : Nossas }}$ estratégias são o reflexo da reação às dificuldades impostas pelo ambiente" $(0,687 / 47 \%)$ e " $\mathrm{X}_{25}$ : À época da adoção da estratégia, as opções estratégias eram limitadas, logo pode-se dizer que a alternativa adotada praticamente se impôs" $(0,604 / 37 \%)$, demonstra novamente que a visão de Porter (1980 e 1985) da influência do contexto ambiental no processo de formação de estratégias é confirmada pelas IES respondentes.

Por esta análise, admite-se que o processo de formação de estratégias das IES pesquisadas apresenta comportamento reativo e impositivo do ambiente, constatação que é sustentada por Porter (1980 e 1985). Esta verificação vai ao encontro das observações analisadas nos indicadores do processo de mudanças, que demonstrou a dependência do processo estratégico das IES respondentes ao contexto ambiental. Esse enfoque no contexto ambiental contraria as considerações de Nicolau (2001) sobre o processo de construção permanente, que valoriza os aspectos psicossociológicos, os valores culturais, criatividade, intuição e visão do estrategista.

$\mathrm{Na}$ análise do processo negociado de formação de estratégias, o único indicador que confirmou ser relevante foi o " $\mathrm{X}_{8}$ : Nossos dirigentes determinam nossa estratégia" $(0,999 / 63 \%)$ fator e comunalidade respectivamente. A influência deste indicador junto ao processo real de formação de estratégias demonstra que parte do processo estratégico das IES pesquisadas é fruto da imposição dos dirigentes, aproximando-se das características da “escola do poder" de Mintzberg; Ahlstrand e Lampel (2000). Nesse mesmo norte refutam-se os aspectos de construção social, indicado por Pettigrew (1977) e Nicolau (2001). 
Paralelamente, o processo real de formação de estratégias não considera a pluralidade de interesses existentes entre os indivíduos e os grupos que se relacionam com a organização, contrapondo a visão integradora do processo negociado de formação de estratégias, que Nicolau (2001) sustenta e que Murray (1978) e March e Simon (1981) ratificam.

As cargas fatoriais dos indicadores em cada grupo geraram índices de comunalidades significativos para a pesquisa, ou seja, capacidade explicativa de cada grupo teórico, que representa a real contribuição das perspectivas teóricas para ilustrar como ocorre realmente o processo de formação de estratégias das IES pesquisadas. Nessa direção foi possível perceber uma ordem de importância, a partir das comunalidades, dos grupos que mais se destacam junto às escolhas estratégicas das IES pesquisadas, conforme apresentado no gráfico 3.

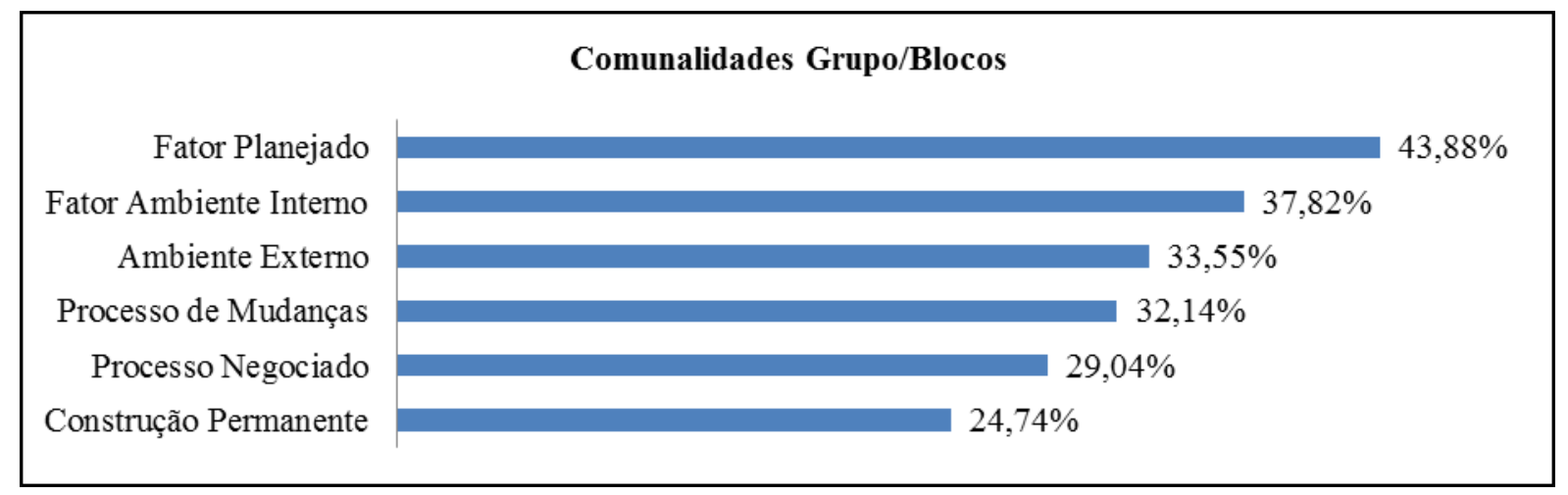

Gráfico 3 Comunalidades dos grupos/blocos teóricos.

Fonte: elaborado pelos autores.

Os indicadores, em conjunto, demonstram que o fator planejado $\left(\mathbf{F}_{\mathbf{1}}\right)$ apresenta a comunalidade explicativa de $43,88 \%$ da variação das respostas obtidas, significa dizer que em torno de $43,88 \%$ do comportamento estratégico das IES respondentes é representado pelo fator planejado de formação de estratégias, configurando-se como o fator de maior contribuição para explicar o processo.

Com a segunda maior carga de comunalidade da pesquisa, o fator ambiente tarefa ( $\left.\mathbf{F}_{5:}\right)$ contribui em 37,82\% da explicação do processo estratégico das IES respondentes, indicando a valorização dos respondentes ao contexto ambiental. Logo, na sequência, aparecem as contribuições explicativas do ambiente geral, que demonstrou uma comunalidade de 33,55\%.

Ainda que não tenha apresentado cargas fatoriais suficientes para constituir-se em fator determinante, verifica-se que a capacidade explicativa dos respectivos indicadores é muito significativa para o processo estratégico das IES respondentes. 
Percebe-se que, entre as características que constituem o processo real de formação de estratégias das IES pesquisadas, o fator ambiente tarefa $\left(\mathbf{F}_{5:}\right)$ e o ambiente geral constituem um grupo de stakeholders que influencia a forma como são criadas as estratégias nas IES, conforme as definições de Freeman (1984); Bonwditch e Buono (1997); Crubellate, Grave e Mendes (2004); Alperstedt, Martignago e Fiates (2006). Há também evidências que enfatizam a importância da compreensão do contexto ambiental conforme as abordagens de Duncan (1972); Porter (1985); Suzrez e Oliva (2005); Cardoso, Bomtempo e Pinto Junior (2006).

O processo de construção permanente, em que pese não tenha apresentado intensidade suficiente para constituir-se em fator, apresentou uma capacidade explicativa de $24,74 \%$. Ou seja, em $24,74 \%$ das IES pesquisadas, as estratégias se impõem ao processo estratégico, sugerindo um comportamento condicionado pelos aspectos ambientais, aceitando, assim as constatações de Duncan (1972); Porter (1985); Suzrez e Oliva (2005); Cardoso, Bomtempo e Pinto Junior (2006) em que as estratégias refletem as forças atuantes no contexto ambiental.

Com capacidade explicativa de $29.04 \%$, o processo negociado indicou que os dirigentes determinam, em grande parte, as estratégias das IES pesquisadas. Essa constatação demonstra que, além da predominância da formalidade do processo planejado e da forte influência do contexto ambiental, o comportamento voluntarista dos dirigentes é algo presente no processo estratégico. Essa constatação demonstra que, em muitos momentos, os interesses das pessoas envolvidas com as IES pesquisadas não são considerados, refutando a premissa de construção social das estratégias que contempla o processo negociado.

Por fim, a análise geral dos 41 indicadores culminou no organograma representado na figura 1 que demonstra o design do processo real de formação de estratégia das IES pesquisadas, a partir das evidências lógicas analisadas até aqui. Observa-se, no centro do organograma, o fator processo planejado de formação de estratégias $\left(\mathbf{F}_{1}\right)$ que é fortemente influenciado pelo fator ambiente tarefa $\left(\mathbf{F}_{5}\right)$ e, consequentemente, pelas variáveis do ambiente geral. Percebe-se que o fator planejado $\left(\mathbf{F}_{1}\right)$ recebe o impacto direto das restrições e dos movimentos do ambiente, verificadas pelas contribuições do processo de mudanças e construção permanente. Constatou-se que o processo estratégico das IES respondentes também é influenciado pela imposição dos dirigentes $\left(\mathbf{X}_{\mathbf{8}}\right)$. 


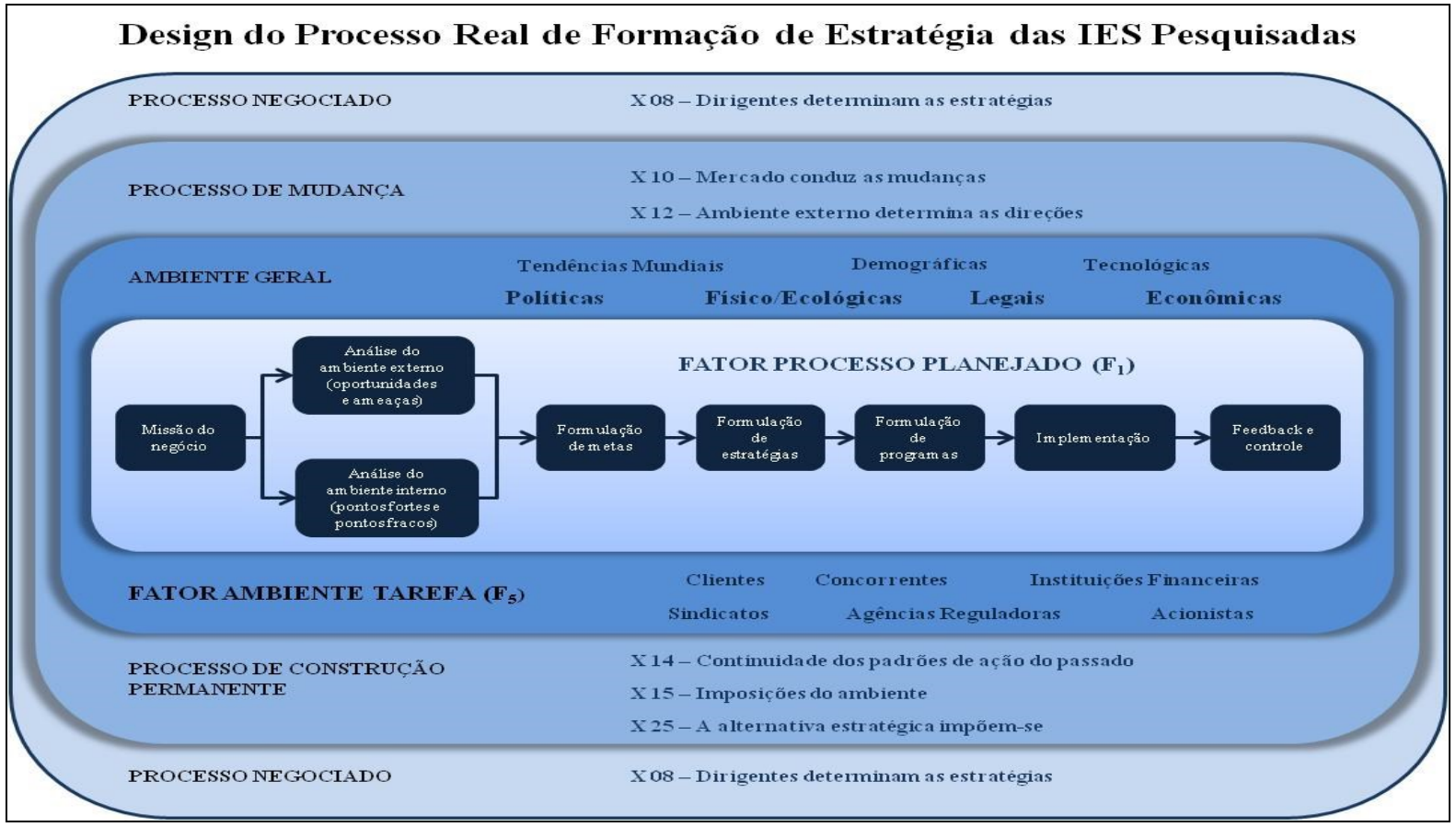

Figura 1 Design do processo real de formação de estratégias.

Fonte: elaborado pelos autores.

A seguir apresenta-se o comportamento das IES.

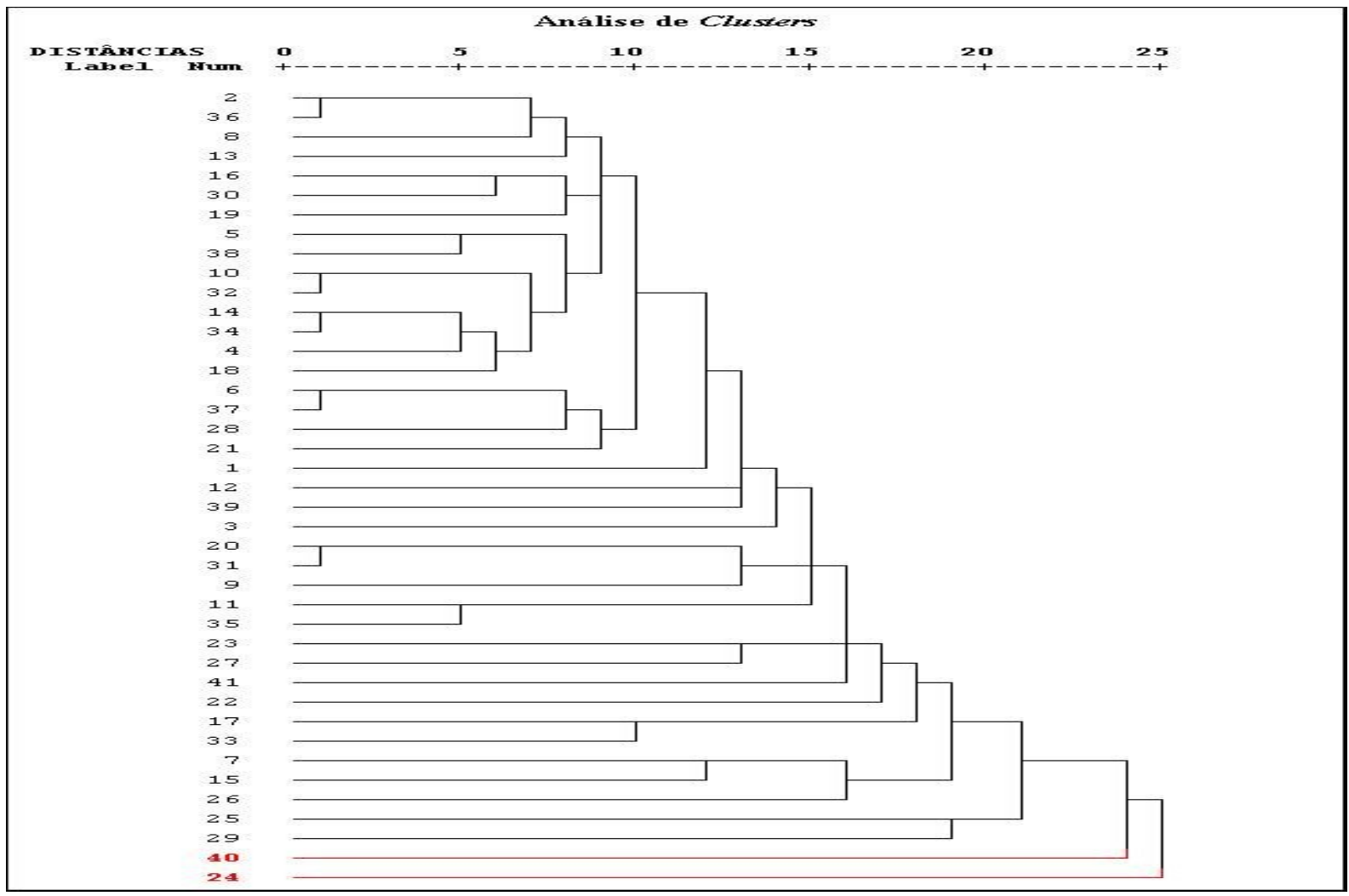

Figura 2 Análise de clusters.

Fonte: elaborado pelos autores. 
Acima apresenta-se o comportamento das IES respondentes em relação à formação de cluster e de conglomerados, por meio da análise multidimencional (MDS). Atraves da análise clusters, o software SPSS gerou o padrão de comportamento das IES respondentes levando em consideração a padronização das respostas obtidas. A intenção desta análise é identificar a formação de grupos por meio da análise das semelhanças e diferenças existentes entre suas características, conforme Oliveira (2007).

A escala vertical da figura 2 representa as IES respondentes destacadas por um número de identificação gerado a partir da ordem de retorno dos questionários respondidos. $\mathrm{Na}$ parte superior da figura encontra-se a escala numérica das distâncias obtidas entre as respostas, que varia de 0 (zero) a 25 (vinte e cinco). As linhas horizontais e respectivas conexões, representam os elos encontrados pela padronização das respostas. O ponto de convergência entre as IES respondentes pode ser visto próximo da escala 25 (vinte e cinco), momento em que houve o agrupamento padronizado das respostas, demonstrando que todas as IES conectadas por linhas pretas, indicam ter respostas dentro dos limites 25 (vinte e cinco), apontando proximidades, ou seja, um padrão de respostas similar.

Apenas duas IES, a 40 e a 24 representadas por linhas vermelhas, registram padrão de respostas que se distancia das demais respondentes. Curiosamente, as duas IES caracterizamse e assemelham-se pelas respectivas concepções acadêmicas e jurídicas, tratam-se de duas IES com perfil confessional protestante, sem fins lucrativos. Fato que constata as incongruências das respostas em relação aos outros elementos da amostra. É possível dizer que as respostas obtidas apresentaram um comportamento aproximado em 39 das IES do total de 41 pesquisadas, patenteando, por esta análise, que 97,8\% das IES respondentes apresentam comportamento similar. As duas IES isoladas revelaram respostas discrepantes das demais, sugerindo comportamento distinto em relação ao processo de formação de estratégias. Assim, constata-se que esta pesquisa apresentou três cluster: um com 39 IES, e os outros dois com uma IES cada um. A análise multidimensional (MDS) buscou verificar a distribuição espacial das IES respondentes de forma a reconhecer agrupamentos e relações entre elas, determinando a imagem relativa percebida pelas respostas e as distâncias representadas num espaço multidimensional, de acordo com ponderações de Pereira (2004) e Oliveira (2007). Nesse compasso apresenta-se a seguir o mapa multidimensional gerado pelo software SPSS das IES pesquisadas. Apura-se no mapa multidimensional, representado pela figura 3 a distribuição das IES representadas pelos respectivos números que foram ordenados de acordo com o retorno das pesquisas, antecedidas pela letra "A". 


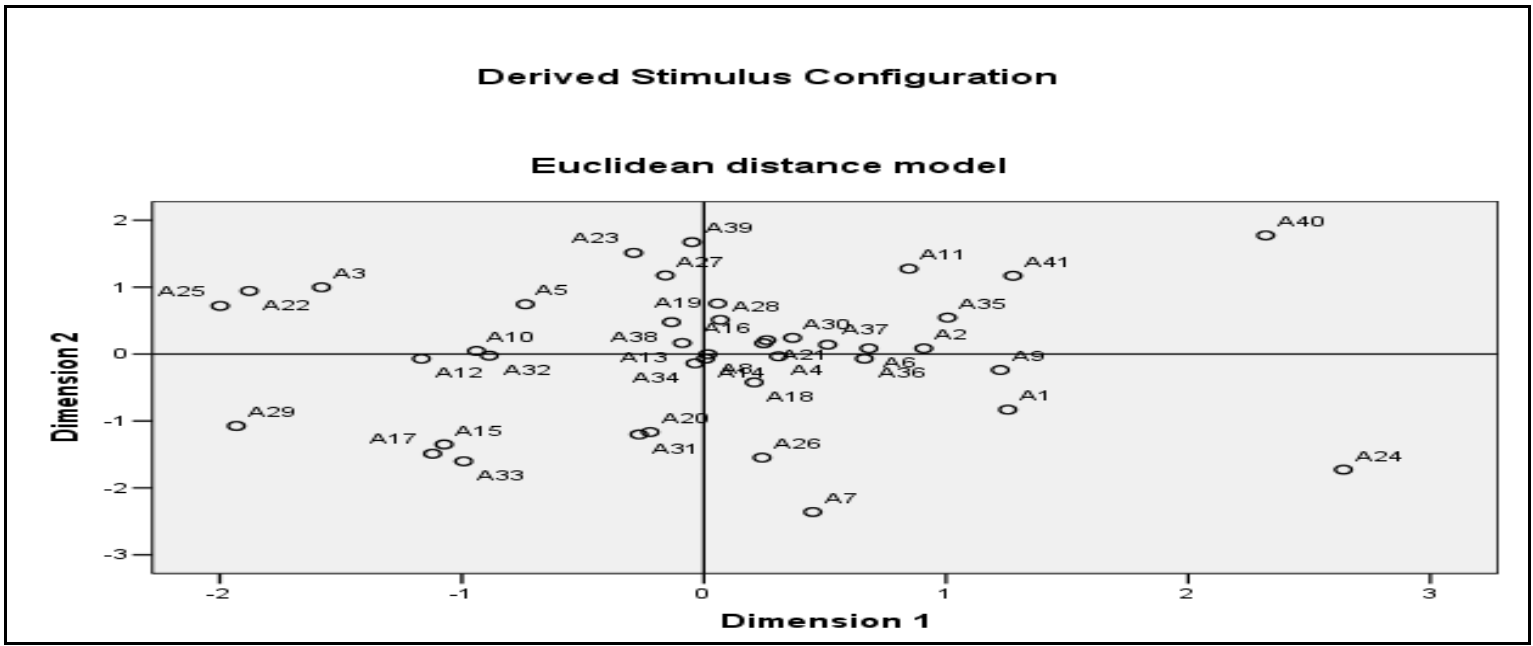

Figura 3 Análise miltidimensional.

Fonte: elaborado pelos autores.

Observa-se, na figura 3, que o escalonamento multidimensional, neste estudo, não modificou o design apresentado na análise de clusters, demonstrando que a maioria das IES pesquisadas apresenta proximidade de respostas. Atesta-se, no mapa que esta maioria concentra-se entre a escala 1 e -2 variações que indicam grande conglomerado com 39 IES respondentes. Neste contexto, mostraram comportamento discrepante as IES “A40" e "A24". As duas situam-se em torno da escala 3, situando-se na extrema direita do mapa, a IES "A40" na parte superior e a IES “A24” na parte inferior. Constatando que as respostas atribuídas por estas IES nesta pesquisa, sinalizam um processo estratégico discrepante em relação às outras IES da amostra. Ratificam-se, em face disso, os resultados da análise de clusters, evidenciando-se na análise multidimensional a formação de três conglomerados com o mesmo padrão dos clusters, constituídos pelas mesmas IES.

\section{CONSIDERAÇÕES FINAIS}

Neste trabalho registram-se os resultados da pesquisa feita com o objetivo de conhecer melhor a realidade do processo de formação de estratégias nas IES do Estado de Santa Catariana. Para este intento, utilizou-se uma pesquisa quantitativa do tipo survey, por conseguinte, a análise dos dados valeu-se da estatística multivariada, elemento que permitiu maior acurácia na observação das informações coletadas.

Em resposta ao problema de pesquisa, os resultados deste estudo indicaram que as IES de Santa Catarina respondentes enxergam o seu processo estratégico como majoritariamente sustentado pelo processo planejado de formação de estratégias, afastando-se assim do 
processo como formação e aproxima-se do processo como formulação de estratégias, concernente as definições de Mintzberg (1978); Mintzberg, Ahlstrand e Lampel (2000) e Mintzberg; Quin, (2001). A formalidade é um elemento presente e preponderante no processo, aspecto que é fruto do processo sistemático e processual de formação de estratégias, não obstante existem evidências que há estratégias que se aproximam do padrão emergente.

O processo demonstrou ser apolítico, contrariando as perspectivas da teoria institucional de Pettigrew (1977) e do processo negociado de formação de estratégias caracterizado por Nicolau (2001), as estratégias apresentam tímida relação com padrões do passado, sugerindo nuances de aprendizado, conforme ponderado por Idenberg (1993) e ratificado por Mintzberg; Ahlstrand; Lampel (2000); as estratégias são predominantemente determinadas pelo ambiente (comportamento determinista), indicando conduta reativa em relação às demandas estratégicas, ratificando os argumentos de Aldrich e Pfeffer (1976); Hinings e Greenwood (1989); Hit e Tyller (1991); Amenarkis e Bedeian (1999); Hall (1984) em que as estratégias são determinadas por pressões do contexto ambiental, há momentos, no entanto que há interferência explícita dos dirigentes, impondo as estratégias.

Um grupo significativo de stakeholders foi identificado como influentes no processo de formação de estratégias, demonstrando a interferência do contexto ambiental no comportamento estratégico das IES pesquisadas, argumentos que Duncan (1972) e Porter (1980 e 1985) desenvolveram apontando a importância da verificação do contexto ambiental no processo de formação de estratégias, ótica que Freeman (1984) e Bonwditch; Buono (1997) ampliaram para a perspectiva dos stakeholders. Essas constatações contrariam algumas expectativas deste trabalho, porque em razão das características do corpo social envolvido na gestão destas IES, o processo estratégico deveria apresentar comportamento mais próximo dos padrões de estratégias emergentes, de perfil voluntarista, dotado de capacidade política de negociação, em que valorizasse a interação dos indivíduos para a construção da melhor alternativa estratégica.

É possível que o olhar mais cuidadoso das IES ao contexto ambiental tenha relação com as consequências que a Lei de Diretrizes e Bases para a Educação Nacional n. 9.394/96, desencadeou para o setor de educação superior. Houve intenso crescimento e proliferação de IES no país, por conseguinte, em Santa Catarina.(ESTEVES, 2007; INEP/MEC, 2008). Nesse contexto, Steiner (2010) sublinha que as IES de caráter privado, com fins lucrativos, foram as que mais ampliaram suas atividades, fato que pode estar indicando comportamento competitivo entre as IES de modo geral, independente de serem com fins lucrativos ou não. 
Este cenário competitivo pode justificar, em parte, a alta ênfase das IES respondentes ao contexto ambiental, especialmente na caracterização do amplo e significativo grupo de stakeholders identificados como influentes em seu processo estratégico. No ambiente tarefa as IES identificaram: sindicatos, agências reguladoras, clientes, concorrentes, instituições financeiras e acionistas. No ambiente geral, foram identificados: políticas, tendências mundiais, aspectos físico/ecológicos, variáveis econômicas, tecnologias, aspectos legais e características demográficas. Os stakeholders podem ser caracterizados como aspectos motivacionais no processo estratégico das IES respondentes, corroborado pelo olhar aguçado das pesquisadas ao contexto ambiental.

De modo menos significativo aparece a indicação de um processo que valoriza padrões do passado, próximo de um processo contínuo de formulação e implementação por meio da tentativa e erro. Neste norte o processo estratégico tem algumas semelhanças com o processo de aprendizagem, deliado por Mintzberg, Ahlstrand; Lampel (2000), de elementos que podem gerar estratégias emergentes ou deliberadas dependendo das condições em que são construídas. Confirmando as expectativas do incrementalismo lógico desenvolvido por Idengurg (1993) em que a base é a formação de estratégias por meio de modelos incrementais contínuos.

Por fim, averiguou-se que o processo estratégico das IES pesquisadas se orienta primordialmente pelo processo planejado, formal, deliberado, determinista, apolítico, imposto pelo ambiente com forte influência dos stakeholders, com tímida concentração no aprendizado e, em certa medida, condicionada pelos dirigentes. Esta possibilidade de análise crítica acerca o modo como são construídas as estratégias pode estimular melhorias no desempenho das IES frente às constantes mudanças que o setor está envolvido, lição extraída de Meyer e Murphy (2000); Vahl; Meyer e Finger (1989); Sampaio e Laniado (2009).

\section{REFERÊNCIAS}

ALPERSTEDT, G. D. CUNHA, C. J. C. A. Adaptação estratégica em organizações universitárias: um estudo de caso na Universidade do Sul de Santa Catarina. In: XXIII

ALPERSTEDT, G. D.; MARTIGNAGO, G.; FIATES, G. G. S. O processo de adaptação estratégica de uma Instituição de Ensino Superior sob a ótica da teoria institucional. Revista de Ciências da Administração, Florianópolis, v.8, n.15, jan/jun. 2006.

AMENARKIS, AA; Buckley, MR. BEDEIAN, AG. Organizational change: a review of theory and research in the 1990s. Journal of Management, 25 (3), p.293-315, 1999. 
ANASTÁCIO, M. R. Mudanças no ambiente político-legal e formulação estratégica de Universidades: um estudo comparativo de casos em Fundações Educacionais de Santa Catarina. 2003. 178f. Dissertação (Mestrado em Administração) - PUC/PR, Curitiba, 2003.

ANSOFF, H, I. Critique of Henry Mintzberg's The Design School: Reconsidering the basic premises of strategic management. Strategic Management Journal, v.12, p. 449-461, 1990.

BERTUCCI, J. L. O. Estratégias e performance organizacional em Instituições de Ensino Superior: as PUCs brasileiras em busca de efetividade. São Paulo: PUC, 2001.

BEPPLER, M. K.; PEREIRA, M. F.; COSTA, A. M. Discussão conceitual sobre o processo de estratégia nas organizações: formulação e formação estratégica. Revista Ibero-Americana de Estratégia, São Paulo, v.10, n.1, p.128-147, jan/abr.2011.

BOWDITCH, J. L., BUONO, A. F. Elementos de comportamento organizacional. São Paulo: Pioneira, 1997.

BRASIL. Censo do Ensino Superior 2005. 2006. Disponível em: < www.inep.gov.br $>$. Acesso em: 02 dez 2009.

CARDOSO, L. G.; BOMTEMPO, J. V.; PINTO JUNIOR, H. Q. Compreendendo o crescimento das firmas: ferramentas de análise baseadas em Chandler e Penrose.

Organização \& Sociedade. Salvador, v.13, n.37, abril/jun. 2006.

CHANDLER, A. Strategy and structure. MA: MIT Press, 1962.

CRUBELlATE, J. M.; GRAVE, P. S.; MENDES, A. A. A questão institucional e suas implicações para o pensamento estratégico. Revista de Administração Contemporânea RAC, Curitiba, v. 8, Edição Especial, p. 37-60, 2004.

CYRINO, J.; MARTINS, O.; OLIVEIRA, A.; SILVA JUNIOR, H. Estratégias competitivas de IES privadas capixabas: uma análise setorial dos cursos de administração. In: SIMPÓSIO DE EXCELÊNCIA EM GESTÃO E TECNOLOGIA, 2, 2008, São Paulo. Anais...São Paulo: FUCAPE Busines School, 2008.

DUNCAN, R. Characteristics of organizational environments and perceived environmental uncertainty. Administrative Science Quarterly, v. 17, n. 3, p. 313-327, 1972.

ESTEVES, P. C. L. Fatores determinantes de mudanças na estrutura competitiva do sistema de ensino superior de Santa Catarina. 2007. 154f. Tese (Doutorado em Engenharia da Produção) - Universidade Federal de Santa Catarina, Florianópolis, 2007.

FORTE, S. H. A. C.; NOGUEIRA, E. M. M. M.; Posicionamento estratégico das IES cearenses: Um estudo quantitativo. In: XXX ENCONTRO NACIONAL DA ASSOCIAÇÃO NACIONAL DE PÓS-GRADUAÇÃO EM ADMINISTRAÇÃO - ENANPAD, 30, 2006, Salvador. Anais...Salvador: ANPAD, 2006.

FREEMAN, R. E. Strategic management: a stockholders approach. Boston Pitman, 1984. HALL, R. Organizações: Estruturas e Processos. $3^{\text {a }}$ ed. Rio de Janeiro: Prince Hall do Brasil, 1984.

HITT, M. A.; TYLER, B. B. Strategic decision models: integrating different perspectives. Strategic Management Journal, v. 12, p. 327-351, 1991. 
HOFER, C. W.; SCHENDEL, D. Strategy formulation: Analytical concepts, West Publishing Company, 1978.

IDENBURG, P. J. Four Styles of Strategy Development, Long Range Planning: Vol. 26, 1993.

LEVINE, D.M.; BERENSON, M.L.; STEPHAN, D.Estatística: teoria e aplicações. 3. ed. Rio de Janeiro : L.T.C., 2005.

LDB - Lei das Diretrizes e Bases da Educação Nacional n. 9.394, de 20 de dezembro de 1996. Diário Oficial da União, Brasília, DF, 23 dez. 1996. Seção 1, p.27.839.

MAINARDES, W. E.; ALVES, H.; RAPOSO, M.; DOMINGUES, M. J. C. S. Quem são os stakeholders de uma Universidade? In: VI ENCONTRO DE ESTUDOS

ORGANIZACIONAIS DA ASSOCIAÇÃO NACIONAL DE PÓS-GRADUAÇÃO EM ADMINISTRAÇÃO, 6, 2010, Florianópolis. Anais...Florianópolis: ANPAD, 2010.

MARCH, James G. SIMON, Herbert A. Teoria das Organizações. 4. ed. Rio de Janeiro: Fundação Getúlio Vargas, 1981.

MAROCO, João. Análise estatística com utilização do SPSS. Lisboa: Editora Manuel Robalo, 2010.

MEYER, V. JR.; MURPHY, JP. Dinossauros, gazelas e tigres: novas abordagens da administração universitária. São Paulo: Insular, 2000.

MINTZBERG, H.; QUINN, J. B. O processo da estratégia. 3. ed. Porto Alegre: Bookman, 2001.

OLIVEIRA, Francisco Estevam Martins. SPSS Básico para análise de dados. Rio de Janeiro: Editora Ciência Moderna Ltda., 2007.

PEREIRA, J. C. R. Análise de dados qualitativos. São Paulo: Editora da Universidade de São Paulo, 2004.

PETTIGREW, A.M. Strategy formulation as a political process. International Studies of Management \& Organization, v. 7, n. 2, p. 78-87, summer, 1977

PORTER, M. E. Competitive strategy: techniques for analyzing industries and competitors. New York : Free Press, 1980.

SAMPAIO, R. M.; LANIADO, R.N. Uma experiência de mudança da gestão universitária: o percurso ambivalente entre proposições e realizações. Revista de Administração Pública RAP, Rio de Janeiro, v.43, p. 151-174, jan/fev. 2009.

SIMON, H. A. Administrative behavior: a study of decision-making processes. New York: MacMillan, 1947.

SUAREZ, F. F.; OLIVA, R. Environmental change and organizational transformation. Industrial and Corporate Change, Oxford University Press on behalf of Associazione ICC. v.14, n.6, pg. 1017-1041, out. 2005.

VAHL, T.; MEYER J. V.; FINGER, A. P. Desafios da administração universitária. Florianópolis: Editora UFSC, 1989. 